\title{
Understanding the maturation process for field investigations of fisheries-induced evolution
}

\author{
P. J. Wright* \\ FRS Marine Laboratory, PO Box 101 Victoria Road, Aberdeen AB11 9DB, UK
}

\begin{abstract}
The probabilistic maturation reaction norm approach has been widely heralded as an empirical approach to distinguish between the effects of genetic selection and phenotypic plasticity on maturation probability. However, applications of this approach have considered maturation state in relation to fish size long after the period when fish make the 'decision' to mature. Evidence, mostly from salmonids, indicates that maturation is controlled by successive hormonal inhibition linked to energy state during critical periods of the year. Thus, any genetic selection cannot be acting upon the size of fish late in the reproductive cycle, but rather during the timing of these critical periods. Indeed, experimental studies demonstrate that size attained by late stages of gametogenesis need not necessarily be a good predictor of the probability of maturing. Therefore, changes in energy status around the time of maturation decisions represent an unknown and possibly significant source of variability in the reaction norm midpoints. Clearly, there is a need to apply physiologically realistic models of maturation probability - as have been developed for Atlantic salmon - to other fish species. Future investigation of fisheries-induced evolution may also benefit from examining historical changes in fecundity and by comparing current reproductive investment in fish from heavily and lightly exploited populations that are held under common-garden conditions.
\end{abstract}

KEY WORDS: Maturation $\cdot$ Fecundity $\cdot$ Fisheries-induced evolution $\cdot$ Critical periods

\section{INTRODUCTION}

Long-term shifts in life-history traits of fish, particularly a trend towards decreasing size and age at maturity, have been widely reported in heavily exploited fish stocks (Law 2000). Genetic selection generated by fishing has long been considered an important contributory factor to these changes (Ricker 1981, Trippel 1995, Law 2000). Controlled selection experiments have confirmed this potential for harvest-induced genetic change in life-history traits (Conover \& Munch 2002). However, expressed life-history traits will be influenced not only by genetics but also by environmental variation through phenotypic plasticity. Distinguishing between the effects of genetic selection and phenotypic plasticity in wild fish populations is, therefore, a major challenge. Owing to the potential longterm impact of fisheries-induced evolution on the yield of fish stocks (Conover \& Munch 2002), it is essential that we evaluate the relative contributions of genetic and environmentally induced variation on the observed phenotypic changes (Rochet et al. 2000).

The probabilistic maturation reaction norm (PMRN) approach was developed to provide a method for distinguishing the effects of genetic variation and growthinduced phenotypic plasticity on maturation. This method models the probability of maturing within a cohort based on the proportion of immature and mature individuals at a given size and age (Heino et al. 2002). By accounting for size at age, the probability of maturing is independent of variations in growth and survival that confound maturity-size relationships. Changes in the reaction norm mid-point have been interpreted as evolutionary shifts in maturity at size (Barot et al. 2004, Olsen et al. 2004). However, the PMRN approach has 2 important limitations. First, whilst the probabilistic treatment acknowledges that maturation cannot be fully accounted for by length and age alone, these are the only 2 parameters considered in the majority of published studies. Although this 
problem may be overcome with additional information on the energetic status of the fish, such as an index of condition, there is a second and more fundamental problem. The developmental 'decision' to spawn takes place long before spawning actually happens, yet applications of this method have been based on measurements taken on fish in advanced stages of reproductive development (Grift et al. 2003, Barot et al. 2004). Thus, the relationship between maturity and size used within the formulation of PMRNs reflects the outcome of the fish's continued gonadal development rather than its state when the initial maturation decision was made. To fully appreciate the consequence of this assumption, it is important to understand the proximate influences on maturation.

\section{THE MATURATION PROCESS}

There is now substantial evidence that maturation is not dependent on size thresholds or growth per se but rather is sensitive to an animal's growth and energetic status at particular times of year. The importance of time of year is evident from the ability to shift or even inhibit maturation by means of photoperiod manipulation (e.g. Shimizu et al. 1994, Bromage et al. 2001, Norberg et al. 2004). Photoperiod appears to alter the timing of the period when the physiological threshold must be exceeded for maturation to continue (Bromage et al. 2001). As Thorpe (2007, this Theme Section) describes for salmonids, maturation is controlled by successive inhibition through lipid-regulated switches during critical periods of the year (see also Silverstein et al. 1997). Whilst the physiological changes in the pituitary-gonad axis associated with these critical periods are still under investigation, it does appear that the insulin-like Growth Factor 1 signals the growth and nutritional status (Campbell et al. 2003, 2006), thus stimulating the release of hormones such as folliclestimulating hormone and sex steroids (Campbell et al. 2003, 2006, Gen et al. 2003) involved with early gametogenesis.

Evidence that size attained by the late stages of gametogenesis is not necessarily a good predictor of the probability of maturing comes from laboratory experiments that followed the growth of size-matched groups of juveniles of the same age through to adulthood. Fig. 1 provides 2 such examples following fish growth from primary to secondary phases of oogenesis. The appearance of cortical alveoli vesicles containing yolk proteins generally indicates that oocytes will continue developing through to the secondary phase (true vitellogenesis) and subsequent spawning at the next breeding season. In these experiments, maturityrelated differences in final length are clearly not related to fish size by the cortical alveoli phase of oocyte development. Fish that go on to mature in such experiments are characterised by high somatic growth and condition prior to the secondary phases of gametogenesis (Imsland et al. 1997, Yoneda \& Wright 2005). Thus, size differences between mature and immature fish by the spawning season reflect an initially higher somatic growth rate in those that matured, followed by depressed somatic growth associated with the energy allocation to the secondary phase of gametogenesis (Yoneda \& Wright 2005).

Whilst the PMRN assumes that a shift in the midpoint of the reaction norm can reflect a genetic effect, it is clear from the previous sections that any genetic selection cannot be acting on the size of fish late in the reproductive cycle. Thorpe (1986) proposed that genetic control is likely to act via the lipid/energy sensitive switches involved in the initial maturation decisions. Support for active inhibition of maturation has come from differences in the expression of genes involved in growth and reproduction between early maturing male, immature female and immature male Atlantic salmon Salmo salar (Aubin-Horth et al. $2005 a, b)$. Therefore, if there has been a genetic change in maturation tendency, this would be expected to have acted on the threshold switches for maturation. Whilst the PMRN approach considers annual growth, it does not account for the effect of growth or lipid stores at the time of developmental decisions. Therefore, for the PMRN approach to have relevance to maturation decisions, it is necessary to demonstrate that the measurements used - i.e. maturity at pre-spawning length and annual growth increments - are correlated with proximate thresholds for maturation. This would require a close correlation between final length and lipid accumulated during the period when maturation decisions are made in wild fish.

There is often a close correlation among fish size, growth and primary lipid stores. For example, in salmonids, visceral fat level is often correlated with length (Simpson 1992), whilst in gadoids relative liver weight is generally related to somatic growth rate (Jobling 1988). As such, energy-dependent thresholds may covary with pre-spawning length and the annual growth increment measurements used for PMRNs. Nevertheless, mature fish tend to have a much higher liver energy than immature fish for a given size (Eliassen \& Vahl 1982), and there can be large interannual variations in the relationship between liver size and fish size (Yaragina \& Marshall 2000). Consequently, individual differences in lipid accumulation and storage around the time of maturation decisions could introduce a significant source of variation in the size at which fish initially 'decide' to mature. Measurement of the effects of this variation made just prior to 

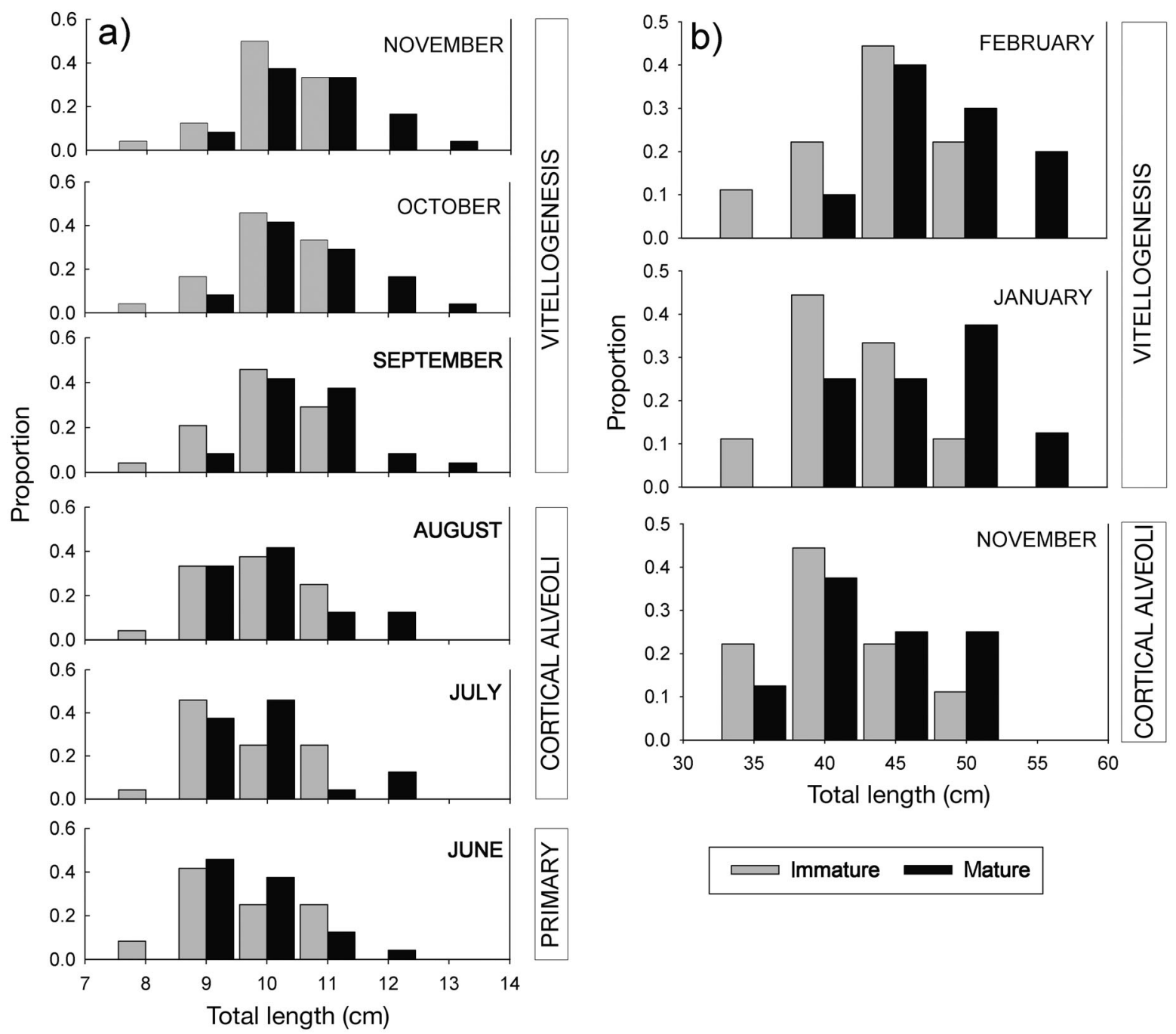

Fig. 1. Changes in proportional length composition of a group of (a) Ammodytes marinus (P. Boulcott \& P. Wright unpubl. data) and (b) Gadus morhua (Yoneda \& Wright 2005) reared under identical laboratory conditions. Data presented separately for mature and immature fish, based on assessment of gonad stage at the end of experiments. Periods during which primary, cortical alveoli and vitellogenic oocytes appear are indicated based on sub-samples taken throughout experiments

spawning suggests that lipid energy can account for an additional but comparatively small amount of the variation in maturity relative to size (Marteinsdottir \& Begg 2002, Morgan 2004). However, because these studies were conducted in the late phases of gametogenesis, they may have little relevance to the effect of lipid energy at the time of maturation decisions. Therefore, changes in energy status around the time of maturation decisions represent an unknown and possibly significant source of variability in the reaction norm midpoints. If such variability exhibited a long term trend, then it might explain some of the apparent decline in reaction norm midpoints reported in some studies.

The ability to calculate PMRNs using just 2 parameters that are readily available for many fish stocks has made this a popular approach in the search for fish- eries-induced evolution. However, the focus on the outcome size at age, well after maturation decisions have been made, is a serious source of uncertainty in the PMRN approach. A better understanding of the timing of maturation decisions may help identify more appropriate sample data sources and times for collection. If information on energetic status around the time of the maturation decisions was available for some stocks, then it may be possible to develop a more physiologically realistic model of maturation probability, as proposed by Day \& Rowe (2002) and developed for Atlantic salmon (Thorpe et al. 1998). Owing to our limited knowledge of the maturation process for most species, it is clearly not possible to assess how changes to the timing of measurements of size or energetic status would influence estimates of reaction norm mid- 
points. Changes in reaction norm midpoints of a similar magnitude to a fish's annual growth, such as that reported for Atlantic cod Gadus morhua from Georges Bank (Barot et al. 2004), certainly would suggest a substantial change in growth and therefore the statedependent threshold for maturation. However, other explanations need to be explored, as suggested by the study of Marshall \& McAdam (2007, this Theme Section) on liver energy variation in Northeast Arctic cod.

\section{CHANGES IN REPRODUCTIVE INVESTMENT}

In addition to the focus on maturation changes, future investigation of fisheries-induced evolution may benefit from examining other aspects of reproductive investment. In terms of life-time reproductive output, an individual maturing at a smaller size would have to invest more heavily in egg production with age if it is to compensate for the initial size effect on fecundity. Ultimately, this may lead to selection for higher fecundity at maturity and an increase in the slope of the fecundity-size relationship (Rochet et al. 2000). Evidence that increases in relative fecundity and lower body condition have occurred in heavily exploited stocks has come from studies of Atlantic cod (Yoneda \& Wright 2004, Lambert et al. 2005) and haddock Melanogrammus aeglefinus (Wright 2005). However, as with maturation, disentangling environment and genetic effects on fecundity is difficult. It may be possible to determine the nature and magnitude of changes necessary to differentiate between a phenotypic and genetically determined effect on fecundity-size relationship in the field, based on knowledge of the proximal influences on fecundity gained from laboratory studies. For example, laboratory studies have demonstrated that the fecundity of first-time spawning Atlantic cod is closely correlated with body weight, regardless of the growth conditions that a fish is subjected to (Kjesbu \& Holm 1994, Karlsen et al. 1995, Yoneda \& Wright 2005, Skjæraasen et al. 2006). In contrast, the fecundity of repeat spawning Atlantic cod can be highly modified by feeding conditions prior to spawning (Kjesbu et al. 1991). Consequently, from this knowledge it would seem likely that temporal changes in fecundity at weight in first-time spawners is more indicative of a genetic change in reproductive investment than changes in the fecundity of repeat spawners.

Further evidence for the potential for fisheriesinduced evolution to occur may come from a comparison of reproductive investment between heavily and lightly exploited populations. There is increasing evidence of population-specific differences in life-history traits from field investigations, including maturity and fecundity at size (Marteinsdottir \& Begg 2002, Olsen et al. 2004, Yoneda \& Wright 2004). Whilst much of the variability may be environmentally induced, commonenvironment experiments indicate the existence of genetically determined differences in some traits. For example, apparent genetic differences in some growth-linked parameters have been found between and within Atlantic silverside Menidia menidia (Conover et al. 2005) and Atlantic cod stocks (Purchase \& Brown 2001, Salvanes et al. 2004). It may therefore be useful to contrast the state-dependent thresholds for maturation decisions among populations and then relate any differences to exploitation history.

Acknowledgements. Comments on an earlier draft of the essay by Drs. F. Neat and C. T. Marshall are greatly appreciated. This work was supported by Scottish Executive Project MF 07a.

\section{LITERATURE CITED}

Aubin-Horth N, Landry CR, Letcher BH, Hofmann HA (2005a) Alternative life histories shape brain gene expression profiles in males of the same population. Proc R Soc Lond B 272:1655-1662

Aubin-Horth N, Letcher BH, Hofmann HA (2005b) Interaction of rearing environment and reproductive tactic on gene expression profiles in Atlantic salmon. J Hered 96: 261-278

Barot S, Heino M, O'Brien L, Dieckmann U (2004) Long-term trend in the maturation reaction norm of two cod stocks. Ecol Appl 14:1257-1271

Bromage N, Porter M, Randall C (2001) The environmental regulation of maturation in farmed finfish with special reference to the role of photoperiod and melatonin. Aquaculture 197:63-98

Campbell B, Dickey JT, Swanson P (2003) Endocrine changes during onset of puberty in male spring chinook salmon, Oncorhynchus tshawytscha. Biol Reprod 69:2109-2117

Campbell B, Dickey J, Beckman B, Young G, Pierce A, Fukada H, Swanson P (2006) Previtellogenic oocyte growth in salmon: relationships among body growth, plasma insulin-like growth factor-1, estradiol-17beta, follicle-stimulating hormone and expression of ovarian genes for insulin-like growth factors, steroidogenic-acute regulatory protein and receptors for gonadotropins, growth hormone, and somatolactin. Biol Reprod 75:34-44

Conover DO, Munch SB (2002) Sustaining fisheries yields over evolutionary time scales. Science 297:94-96

Conover DO, Arnott SA, Walsh MR, Munch SB (2005) Darwinian fishery science: lessons from the Atlantic silverside (Menidia menidia). Can J Fish Aquat Sci 62:730-737

Day T, Rowe L (2002) Development threshold and the evolution of reaction norms for age and size at life-history transitions. Am Nat 159:338-350

Eliassen J, Vahl O (1982) Seasonal variations in biochemical composition and energy content of liver, gonad and muscle of mature and immature cod, Gadus morhua (L.). J Fish Biol 20:707-716

Gen K, Yamaguchi S, Okuzawa K, Kumakura N, Tanaka H, Kagawa H (2003) Physiological roles of FSH and LH in red seabream, Pagrus major. Fish Physiol Biochem 28:77-80 
Grift RE, Rijnsdorp AD, Barot S, Heino M, Dieckmann U (2003) Fisheries-induced trends in reaction norms for maturation in North Sea plaice. Mar Ecol Prog Ser 257: 247-257

Heino M, Dieckmann U, Godø OR (2002) Measuring probabilistic reaction norms for age and size at maturation. Evolution 56:669-678

Imsland AK, Folkvord A, Grung GL, Stefansson SO, Taranger GL (1997) Sexual dimorphism in growth and maturation of turbot, Scophthalmus maximus (Rafinesque, 1810). Aquac Res 28:101-114

Jobling M (1988) A review of the physiological and nutritional energetics of cod, Gadus morhua L., with particular reference to growth under farmed conditions. Aquaculture 70: $1-19$

Karlsen Ø, Holm JC, Kjesbu OS (1995) Effects of periodic starvation on reproductive investment in first-time spawning Atlantic cod (Gadus morhua L.). Aquaculture 133:159-170

Kjesbu OS, Holm JC (1994) Oocyte recruitment in first time spawning Atlantic cod (Gadus morhua) in relation to feeding regime. Can J Fish Aquat Sci 51:1893-1898

Kjesbu OS, Klungsoyr J, Kryvi H, Witthames PR, Greer Walker M (1991) Fecundity, atresia, and egg size of captive Atlantic cod (Gadus morhua) in relation to proximate body composition. Can J Fish Aquat Sci 48:2333-2343

Lambert Y, Kjesbu OS, Kraus G, Marteinsdottir M, Thorsen A (2005) How variable is the fecundity within and between cod stocks? ICES CM 2005/Q:13

Law R (2000) Fishing, selection, and phenotypic evolution. ICES J Mar Sci 57:659-668

Marshall CT, McAdam BJ (2007) Integrated perspectives on genetic and environmental effects on maturation can reduce the potential for errors of inference. Mar Ecol Prog Ser 335:301-310

Marteinsdottir G, Begg GA (2002) Essential relationships incorporating the influence of age, size and condition on variables required for estimation of reproductive potential in Atlantic cod Gadus morhua. Mar Ecol Prog Ser 235: 235-256

Morgan MJ (2004) The relationship between fish condition and the probability of being mature in American plaice (Hippoglossoides platessoides). ICES J Mar Sci 61:64-70

Norberg B, Brown CL, Halldorsson A, Stensland K, Bjornsson BT (2004) Photoperiod regulates the timing of sexual maturation, spawning, sex steroid and thyroid hormone profiles in the Atlantic cod (Gadus morhua). Aquaculture 229: 451-467

Olsen EM, Heino M, Lilly GR, Morgan MJ, Brattey J, Ernande B, Dieckmann U (2004) Maturation trends indicative of rapid evolution preceded the collapse of northern cod. Nature 428:932-935

Purchase CF, Brown JA (2001) Stock-specific changes in growth rates, food conversion efficiencies, and energy

Editorial responsibility: Howard Browman (Associate Editorin-Chief), Storebø, Norway allocation in response to temperature change in juvenile Atlantic cod. J Fish Biol 58:36-52

Ricker W (1981) Changes in the average size and average age of Pacific salmon. Can J Fish Aquat Sci 38:1636-1656

Rochet MJ, Cornillon PA, Sabatier R, Pontier D (2000) Comparative analysis of phylogenetic and fishing effects in life history patterns of teleost fishes. Oikos 91:255-270

Salvanes AGV, Skjaeraasen JE, Nilsen T (2004) Sub-populations of coastal cod with different behaviour and lifehistory strategies. Mar Ecol Prog Ser 267:241-251

Shimizu A, Aida K, Hanyu I (1994) Effects of photoperiod and temperature on gonadal activity and plasma steroid levels in an autumn-spawning Bitterling, Acheilognathus rhombea, during different phases of its annual reproductive cycle. Gen Comp Endocrinol 93: $137-150$

Silverstein JT, Shimma H, Ogata H (1997) Early maturity in amago salmon (Oncorhynchus masu ishikawai): an association with energy storage. Can J Fish Aquat Sci. 54: $444-451$

Simpson A (1992) Differences in body size and lipid reserves between maturing and nonmaturing Atlantic salmon parr, Salmo salar L. Can J Zool 70:1737-1742

Skjæraasen JE, Nilsen T, Kjesbu OS (2006) Timing and determination of potential fecundity in Atlantic cod (Gadus morhua). Can J Fish Aquat Sci 63:310-320

Thorpe JE (1986) Age at first maturity in Atlantic salmon, Salmo salar L.: freshwater period influences and conflicts with smolting. Can J Fish Aquat Sci 89:7-14

Thorpe JE (2007) Maturation responses of salmonids to changing developmental opportunities. Mar Ecol Prog Ser 335:285-288

Thorpe JE, Mangel M, Metcalfe NB, Huntingford FA (1998) Modelling the proximate basis of salmonid life-history variation, with application to Atlantic salmon, Salmo salar L. Evol Ecol 12:581-599

Trippel EA (1995) Age at maturity as a stress indicator in fisheries. Bioscience 45:759-771

Wright PJ (2005) Temporal and spatial variation in reproductive investment of haddock in the North Sea. ICES CM 2005/Q:07

Yaragina NA, Marshall CT (2000) Trophic influences on interannual and seasonal variation in the liver condition index of Northeast Arctic cod (Gadus morhua). ICES J Mar Sci $57: 42-55$

Yoneda M, Wright PJ (2004) Temporal and spatial variation in reproductive investment of Atlantic cod Gadus morhua in the northern North Sea and Scottish west coast. Mar Ecol Prog Ser 276:237-248

Yoneda M, Wright PJ (2005) Effects of varying temperature and food availability on growth and reproduction in firsttime spawning female Atlantic cod. J Fish Biol 67: $1225-1241$

Submitted: August 3, 2006; Accepted: December 8, 2006 Proofs received from author(s): March 2, 2007 